\title{
Agôn
}

Revue des arts de la scène

Critiques | Saison 2016-2017

\section{Avignon, 23 juillet : Ibsen Huis, de Simon Stone}

Lego dramatique

\section{Caroline Châtelet}

\section{(2) OpenEdition}

Journals

Édition électronique

URL : http://journals.openedition.org/agon/4017

DOI : 10.4000/agon.4017

ISSN : 1961-8581

Éditeur

Association Agôn

\section{Référence électronique}

Caroline Châtelet, «Avignon, 23 juillet : Ibsen Huis, de Simon Stone », Agôn [En ligne], Critiques, mis en ligne le 23 juillet 2017, consulté le 23 septembre 2020. URL : http://journals.openedition.org/agon/ 4017 ; DOl : https://doi.org/10.4000/agon.4017

Ce document a été généré automatiquement le 23 septembre 2020

Association Agôn et les auteurs des articles 


\title{
Avignon, 23 juillet : Ibsen Huis, de Simon Stone
}

\author{
Lego dramatique
}

Caroline Châtelet

\section{RÉFÉRENCE}

Ibsen Huis, conception Simon Stone, du 15 au 20 juillet, Cour du lycée Saint-Joseph, Festival d'Avignon

1 «La Maison d'Ibsen » : simple, minimal, ce titre est une sorte de concrétion, résumant à la fois l'ambition et la forme de ce projet de Simon Stone. Réunissant les comédiens du Toneelgroep Amsterdam, Ibsen Huis déploie à l'échelle d'une maison un univers inspiré des pièces du dramaturge norvégien (1828-1906). Comme le déclare le jeune metteur en scène australien dans un entretien - preuve que, parfois, les déclarations d'intention concordent avec la réalité, «Les thèmes et les personnages émanent de l'univers d'Ibsen. Les sources sont plus utilisées comme des atmosphères et donnent le ton moral de la pièce, son orientation possible. Le sens littéral est moins important. Il n'est pas le sujet directement traité. " Ainsi, l'on suit dans cette création Cees, son frère Thomas avec qui il travaille dans son cabinet d'architecte, Daniel fils de Thomas et neveu de Cees, Caroline, sœur de Daniel, et puis les autres frères, sœurs, neveux, petits-enfants. Il y a, d'un côté, des références (Les Revenants, Un ennemi du peuple, Une maison de poupée, Solness le constructeur, Le Canard sauvage, Le petit Eyolf...), qui imprègnent le récit et sont passionnantes à retrouver pour qui connaît l'œuvre du dramaturge (sans qu'elles soient non plus indispensables à la compréhension de ce spectacle). Et il y a la maison, matrice du dispositif narratif, métonymie de l'histoire à venir, personnage principal autant que témoin de ce qui va advenir. D'ailleurs, et à l'image du projet de la maison, l'histoire d'Ibsen Huis, son dispositif et sa structure se déploient comme un jeu de legos. Cette maison, les spectateurs la découvrent en prenant place dans la salle. Une bâtisse qui peut évoquer celle de jeux d'enfants par sa forme cubique et son toit pentu. Une maison également 
séduisante avec son design nordique, son bois clair, ses murs de vitres qui soumettent les espaces communs (cuisine, salon) à tous les regards, seules les chambres demeurant des espaces privés. Disposée sur une tournette, la maison révèle en tournant toutes ses faces et expose ses personnages comme des spécimens. Ce recours ponctuel à la tournette permet dans la première partie les passages d'une période historique à l'autre, tandis qu'il souligne dans la seconde l'implacable mécanique des atrocités. Car de 1964 à 2017, sur trois générations, un peu plus de cinquante ans et dans un seul lieu, c'est la réitération d'horreurs et de violences à l'échelle d'une famille que raconte Simon Stone. Si la première partie emboîte les périodes, la seconde se concentre sur l'origine et la clôture de ces horreurs. Tout débute en 1964, lorsque Cees vole à son neveu la paternité de cette maison à la conception révolutionnaire et y viole Caroline sa nièce de neuf ans. Vol du neveu, viol de la nièce dans une bâtisse encore en construction et avec l'acceptation de l'oncle Thomas, trop faible pour lutter contre son frère : les fondations sont pourries, le terrain est malsain, et rien ne pourra changer cela. A partir de là la mécanique des drames (inceste, violences physiques et psychologiques, meurtre, homophobie, alcoolisme, toxicomanie) va s'enclencher. Virtuoses, les comédiens ne cessent de passer d'un rôle à l'autre, interprétant chacun plusieurs personnages.

2 Avec un art du montage très cinématographique et impeccable par sa maîtrise, Simon Stone entremêle les périodes historiques, et révèle patiemment le système tragique et sa répétition. Si Caroline tente, lorsqu'elle a soixante ans, de reconstruire la maison brûlée dans un incendie - ce projet sera un échec. Le "monument à la résilience " destiné à accueillir des réfugiés ne sera pas terminé, la xénophobie ambiante l'empêchant de voir le jour. Caroline réalise l'impossibilité d'effacer le passé et met le feu à la maison encore en travaux. Avec cet échec se répète la vision sombre d'Ibsen Huis : la destruction et la perversion des enfants par les adultes; la corruption de toute velléité sociale ou humaniste par ces derniers (pensée et conçue par Daniel comme un refuge pour la famille, un espace propice au repos et à l'isolement, la maison devient le réceptacle des atrocités); ainsi que l'impossibilité à la modernité d'émerger, celle-ci étant toujours rattrapée et dénaturée par la tradition réactionnaire (comme l'énonce l'opposition initiale entre Cees, architecte marqué par la tradition réactionnaire et le classicisme, et Daniel architecte moderniste). 